\title{
Blood/Body Fluid Exposure and Needle Stick/Sharp Injury among Nurses Working in Public Hospitals; Southwest Ethiopia
}

\begin{abstract}
Yeshitila Belay Belachew ${ }^{1}$, Tefera Belachew Lema ${ }^{2,3}$, Gugssa Nemera Germossa ${ }^{1}$ and Yohannes Mehretie Adinew4*

${ }^{1}$ Department of Nursing, Jimma University, Jimma, Ethiopia, ${ }^{2}$ Department of Population, College of Public Health and Medical Sciences, Jimma University, Jimma, Ethiopia, ${ }^{3}$ Department of Family Health, College of Public Health and Medical Sciences, Jimma University, Jimma, Ethiopia, ${ }^{4}$ College of Health Sciences and Medicine, Wolaita Sodo University, Sodo, Ethiopia
\end{abstract}

Background: Every health professional around the world is at risk of blood/body fluid exposure and needle stick/sharp injury as a result of exposure to blood or body fluids and needle or sharp injuries. However, the extent of these hazards and their driving forces are not well documented in Ethiopia. Thus, the aim of this study was to assess determinants of blood/body fluid exposure and needle stick/sharp injury among nurses working in Jimma zone, southwest Ethiopia.

Edited by:

Shane Andrew Thomas, Shenzhen International Primary Health Care Research Institute, China

Reviewed by: Daniel Francis Fahey, California State University, San Bernardino, United States Chiara Lorini,

University of Florence, Italy

${ }^{*}$ Correspondence: Yohannes Mehretie Adinew yohannes1979@gmail.com

Specialty section: This article was submitted to Public Health Education and Promotion, a section of the journal Frontiers in Public Health

Received: 17 August 2017 Accepted: 27 October 2017 Published: 27 November 2017

Citation:

Belachew YB, Lema TB, Germossa GN and Adinew YM (2017) Blood/Body Fluid Exposure and Needle Stick/Sharp Injury among Nurses Working in Public Hospitals; Southwest Ethiopia.

Front. Public Health 5:299. doi: 10.3389/fpubh.2017.00299
Methods: An institution-based census was conducted among 318 nurses working in Jimma zone public hospitals from March 10 to 30, 2016. Data were collected by using pretested self-administered questionnaire. Epi info and SPSS were used for data entry and analysis, respectively. Descriptive statistics were done. Bivariate and inter multivariate logistic regression analysis was also carried out to identify predictors of occupational hazards.

Results: The overall prevalence of blood/body fluid exposure and needle stick/sharp injury was found to be 249 (78.3\%). Blood/body fluid exposure and needle stick/sharp injury incidents were reported by 62.6 and $58.8 \%$ of respondents, respectively. Majority of the hazards occurred during morning shift. Being male [AOR: 2.20, 95\% confidence interval (Cl): 1.09, 4.4], being single (AOR: 2.26, 95\% Cl: 1.09, 4.69), and having no training on infection prevention (AOR: $5.99,95 \% \mathrm{Cl}: 3.14,11.41$ ) were positively associated with blood/body fluid exposure and needle stick/sharp injury; while working in chronic illness follow-up clinic (AOR: 0.19, 95\% Cl: 0.05, 0.71) showed negative association at $p$ value of 0.05 .

Conclusion: Prevalence of blood/body fluid exposure and needle stick/sharp injury was high among the nurses. The safety of nurses depends directly on the degree to which nurses can identify and control the varied occupational hazards specific to jobs. Thus, working unit specific safety precautions and basic infection prevention in-service training might improve nurses' safety practice and thereby decrease the on job hazard.

Keywords: occupational hazards, needle stick injury, blood/body fluids, nurses, public hospitals, Ethiopia

Abbreviations: AOR, adjusted odds ratio; COR, crude odds ratio; HCWs, health-care workers; HIV, human immunodeficiency virus; NSI, needle stick injury; OPD, outpatient department; WHO, World Health Organization. 


\section{INTRODUCTION}

Occupational hazard is any condition of a job that can produce a negative effect on peoples' health, either immediately or over time (1). Blood and body fluid exposures and needle stick injuries have been recognized as one of the occupational hazards among health-care workers (HCWs) $(2,3)$. Needle stick injury (NSI) is occupational exposure to patients' body fluids when a needle or other sharp object penetrates the skin and it is interchangeable with sharps injury (4). Occupational hazard places HCWs at risk for numerous blood-borne infections, most importantly human immunodeficiency virus, hepatitis $B$ and $C$ viruses $(5,6)$.

Despite advances in understanding and control of infections, occupational blood and body fluids exposure and NSIs continue to be the major worldwide public health problems (7) and serious concern for around 35 million HCWs globally (8). Biological, chemical, and mechanical hazards are affecting over 20 million HCW annually. Three million health professionals are estimated to be exposed to blood and body fluids due to needle stick or sharps injuries daily (9) and over $90 \%$ of the cases occur in resource constrained countries according to World Health Organization (8). Utilization of safe needle devices can avoid three-fourth of these hazards (9).

Nurses are the major health-care providers in the hospital with more exposure to blood and body fluids (7), as most of their NSIs, the most prevalent occupational hazard, incidents involve devices like hollow-bore needles that are very efficient at transmitting pathogens $(10,11)$. Around two-thirds of disease sero-conversions following NSIs occur among nursing staff (12). The problem is expected to be more devastating in developing countries like Ethiopia where health setup is poor (13).

Information about the prevalence of occupational hazards and its determinants is crucial for occupational health planning. But, little is known about the prevalence of occupational hazards in the study area. Therefore, this study was aimed to assess the prevalence of blood/body fluid exposure and needle stick/sharp injury and associated factors among nurses working in Jimma zone public hospitals, southwest Ethiopia.

\section{MATERIALS AND METHODS}

\section{Study Area and Period}

An institution-based census was conducted among 318 nurses working in three public hospitals in Jimma zone. The hospitals were Shenen Gibe, Limu Genet, and Jimma University Specialized Hospital and all participants have experience of $\geq 6$ months. Jimma is located at a distance of $352 \mathrm{~km}$ from the capital Addis Ababa in the southwest direction. The zone has a total population of 2,486,155; with an area of 15,568.58 square kilometer (14).

\section{Data Collection Instrument and Procedure}

Data were collected using a pretested and structured self-administered questionnaire adopted from previous studies (15-17). Questionnaires were prepared and administered in English as the respondents were professional nurses. The questionnaire consisted of two parts. The first part contains eight questions and was used to assess the sociodemographic characteristics of respondents; the second part includes 15 major items and 47 sub-items for measuring blood/body fluid exposure and needle stick/sharp injury and work-related factors. Nine data collectors guided by one supervisor collected the data from March 10 to 30, 2016.

\section{Data Quality Assurance}

Data quality was controlled by giving training and appropriate supervision for data collectors. The overall supervision was carried out by the principal investigator. The questionnaire was pretested on 18 (5\%) nurses working in Woliso hospital. Based on the pretest analysis, appropriate modifications were made to the questionnaire before the actual data collection.

\section{Data Processing and Analysis}

The filled questionnaires were entered into Epi Info version 3.5.4 after checking for completeness and then exported to SPSS version 20 for further analysis. Descriptive statistics were done. Bivariate and inter multivariate logistic regression models were also carried out. Sex, marital status, age category, training on infection prevention, position in the hospital, and working unit were the variables entered to the multivariate regression. Odds ratios and their $95 \%$ confidence intervals (CI) were computed and variables with $p$-value less than 0.05 were considered significant.

\section{Operational Definitions}

Body Fluid

Body fluid includes vomits, urine, sputum, saliva, amniotic fluid, exudative fluids from burns/lesions, and cerebrospinal fluid.

\section{RESULTS}

\section{Sociodemographic Characteristics of Study Participants}

Out of the expected 341 nurses in selected hospitals, 318 agreed to participate in the study, yielding a response rate of $93.3 \%$. The mean age of the participants was 27.9 years $(S D \pm 6.84)$. Male and single respondents accounted for 50.6 and $54.7 \%$, respectively. More than half 173 (60.7\%) of participants were diploma holders. Majority $229(75.2 \%)$ of them had less than 5 years of work experiences (Table 1). One-fifth (20.1\%) of respondents identified surgical ward as their working unit; followed by outpatient department (19.2\%) and medical ward (17.3\%) (Figure 1).

\section{Prevalence of Blood/Body Fluid Exposure and Needle Stick/Sharp Injury}

The overall prevalence of the hazard was found to be 249 (78.3\%). Around two-third 187 (58.8\%) of the participants reported sharp injuries; syringe needle (58.8\%) and broken ampoule (43.3\%) were the dominants. From the reported sharp injuries, 86 (46.0\%) occurred when the needle was used for an injection and 78 (41.7\%) occurred during ampoule breaking. Out of the 187 nurses exposed to sharp injuries, 72 (38.5\%) had experienced it twice (Table 2).

Almost two-third 199 (62.6\%) of the participants were exposed to blood/body fluids. Of the reported exposures to blood/body fluids, 
177 (88.9\%) involved splashes of blood; whereas 81 (40.7\%) were urine. Most of the exposures occurred during blood drawing 102 (51.3\%), vein puncture 94 (47.2\%), and injection 60 (30.2\%). About one-third $59(29.6 \%)$ of the nurses were exposed twice (Table 3 ).

Though 232 (73\%) of the respondents have no formal training on infection prevention, almost all (99.1\%) of them reported utilization of personal protective devices on duty. Regarding work load, around one-fourth $(23.6 \%)$ of nurses were attending 10 patients per day, while $44(13.8 \%)$ were attending 15 on average.

TABLE 1 | Sociodemographic characteristics of nurses working in Jimma zone public hospitals, southwest Ethiopia, 2016.

\begin{tabular}{llrr}
\hline Characteristics & N $=\mathbf{3 1 8}$ & $\boldsymbol{n}$ & $\%$ \\
\hline Working hospital & Jimma University Specialized Hospital & 273 & 85.8 \\
& Shenen Gibe Hospital & 20 & 6.3 \\
& Limu Genet Hospital & 25 & 7.9 \\
Sex & Male & 161 & 50.6 \\
Age group & Female & 157 & 49.4 \\
& $\leq 24$ years & 106 & 33.3 \\
& 25-29 years & 150 & 47.2 \\
Marital status & $\geq 30$ years & 62 & 19.5 \\
& Married & 136 & 42.8 \\
& Single & 174 & 54.7 \\
Educational qualification & Divorced & 7 & 2.2 \\
& Widowed & 1 & 0.3 \\
Work experiences & BSc & 193 & 60.7 \\
in years & $<5$ years & 125 & 39.3 \\
Position/title in the & $\geq 5$ years & 239 & 75.2 \\
hospital & Staff nurse & 79 & 24.8 \\
& Head nurse & 283 & 89 \\
& Supervisor nurse & 28 & 8.8 \\
& Matron nurse & 4 & 1.3 \\
& & 3 & 0.9
\end{tabular}

Increased exposures to occupational hazards were reported during the morning shift; 111 (59.4\%) sharp/needle stick injuries and 130 (65.3\%) exposure to blood/body fluids (Table 4).

\section{Factors Associated With Occupational Hazards}

Males and single participants conceded increased occupational hazards; while having training on infection prevention and working in chronic illnesses follow-up ward were protective. Age and administrative position in the hospital did not show significant association with occupational hazards. Single respondents were about two times more likely to have occupational hazards than ever married ones (AOR: 2.26, 95\% CI: 1.09, 4.69). The odds of exposure was two times higher for male nurses than their female counterparts (AOR: 2.20, 95\% CI: 1.09, 4.40). Respondents who did not take any training on infection prevention were six times more likely to have occupational hazards than those who did (AOR: 5.99, 95\% CI: 3.14, 11.41). Occupational hazard was found to have significant association with working department where nurses working in chronic illnesses follow-up clinic had $81 \%$ less exposure as compared to nurses working in surgical ward (AOR: 0.190, 95\% CI: 0.05, 0.71) (Table 5).

\section{DISCUSSION}

Despite advances in understanding and control of infections, occupational hazards continued to be the major worldwide public health problem (7). It is the most important problem for HCWs as it increases the risk of infection by exposing them to more than 20 different blood-borne pathogens (18). The problem is more devastating in developing countries like Ethiopia, where health setup is poor (13). Nurses emerge as the staff group reporting the highest proportion of such hazards. Thus,

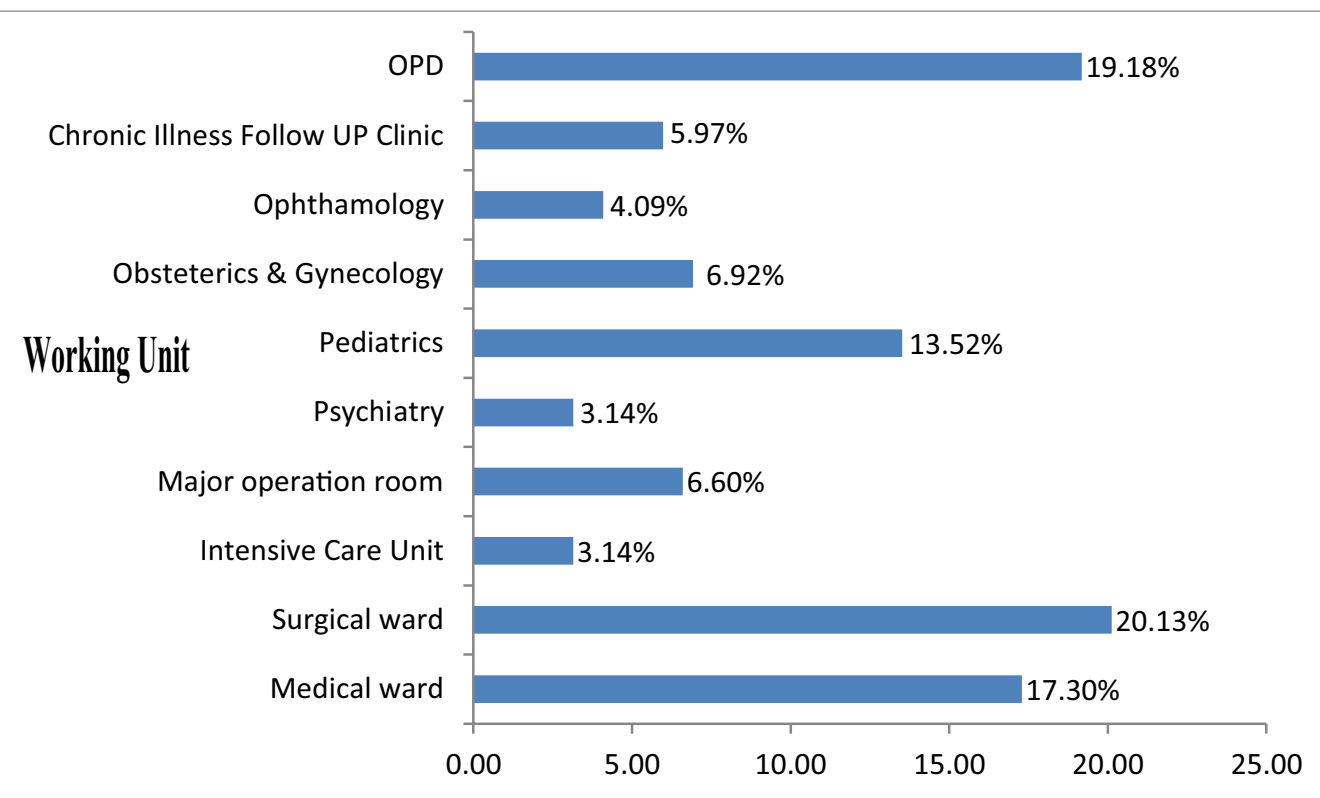

FIGURE 1 | Distribution of nurses working in each unit in Jimma zone public hospitals, southwest Ethiopia, 2016. 
TABLE 2 | Prevalence of needle/sharp injuries in Jimma zone public hospitals, southwest Ethiopia, 2016.

\begin{tabular}{llrr}
\hline & & Yes (\%) & No (\%) \\
\hline Needle stick/sharp injury & & $187(58.8 \%)$ & $131(41.2 \%)$ \\
Types of needle and & Syringe needle & $110(58.8 \%)$ & $77(41.2 \%)$ \\
sharp materials & Suturing needle & $41(21.9 \%)$ & $146(78.1 \%)$ \\
& Butterfly needle & $22(11.8 \%)$ & $165(88.2 \%)$ \\
& IV needle & $47(25.1 \%)$ & $140(74.9 \%)$ \\
& Insulin syringe & $7(3.7 \%)$ & $180(96.3 \%)$ \\
& Lancet & $18(9.6 \%)$ & $169(90.4 \%)$ \\
Types of procedures & Surgical blade & $34(18.2 \%)$ & $153(81.8 \%)$ \\
related to needle stick & Brocken ampoule & $81(43.3 \%)$ & $106(56.7 \%)$ \\
and sharp injuries & Brection & $86(46.0 \%)$ & $101(54.0 \%)$ \\
& Suturing/sewing & $78(41.7 \%)$ & $109(58.3 \%)$ \\
& Blood drawing & $45(24.1 \%)$ & $142(75.9 \%)$ \\
& Needle recapping & $33(17.6 \%)$ & $154(82.4 \%)$ \\
& after use & $14(7.5 \%)$ & $173(92.5 \%)$ \\
& Vein puncture & $56(29.9 \%)$ & $131(70.1 \%)$ \\
& Misplaced needle & $19(10.2 \%)$ & $168(89.8 \%)$ \\
& Disposing & $33(17.6 \%)$ & $154(82.4 \%)$ \\
\hline
\end{tabular}

TABLE 3 | Exposure to blood/body fluids among nurses in Jimma zone public hospitals, southwest Ethiopia, 2016.

\begin{tabular}{llrr}
\hline & & Yes (\%) & No (\%) \\
\hline Blood and body fluid exposures & $199(62.6 \%)$ & $119(37.4 \%)$ \\
Types of blood and body & Blood & $177(88.9 \%)$ & $22(11.1 \%)$ \\
fluids $^{a}$ & Vomit & $66(33.2 \%)$ & $133(66.8 \%)$ \\
& Saliva & $54(27.1 \%)$ & $145(72.9 \%)$ \\
& Urine & $81(40.7 \%)$ & $118(59.3 \%)$ \\
& Amniotic fluid & $7(3.5 \%)$ & $192(96.5 \%)$ \\
& Exudative fluids from & $30(15.1 \%)$ & $169(84.9 \%)$ \\
& burns/lesions & & \\
& Cerebrospinal fluid & $4(2.0 \%)$ & $195(98.0 \%)$ \\
Types of procedure related $_{\text {to blood and body fluid }}$ & Injection & $60(30.2 \%)$ & $139(69.8 \%)$ \\
& Blood drawing & $102(51.3 \%)$ & $97(48.7 \%)$ \\
& Vein puncture & $94(47.2 \%)$ & $105(52.8 \%)$ \\
& Recapping of needle & $12(6.0 \%)$ & $187(94.0 \%)$ \\
& after use & & \\
& Misplaced needle & $12(6.0 \%)$ & $187(94.0 \%)$ \\
& Disposing & $51(25.6 \%)$ & $148(74.4 \%)$ \\
\hline
\end{tabular}

aultiple answers possible (percent do not add 100).

TABLE 4 | Distribution of occupational hazards against working shift among nurses working in Jimma zone public hospitals, southwest Ethiopia, 2016.

\begin{tabular}{|c|c|c|c|c|}
\hline \multirow{3}{*}{$\frac{\text { Variables }}{\text { Working shift }^{\mathrm{a}}}$} & \multicolumn{4}{|c|}{ Types of occupational hazards } \\
\hline & \multicolumn{2}{|c|}{$\begin{array}{c}\text { Needle stick/sharp } \\
\text { injuries }\end{array}$} & \multicolumn{2}{|c|}{$\begin{array}{l}\text { Blood/body fluid } \\
\text { exposures }\end{array}$} \\
\hline & Frequency (n) & $\%$ & Frequency $(n)$ & $\%$ \\
\hline Morning & 111 & 59.4 & 130 & 65.3 \\
\hline Evening & 64 & 34.2 & 79 & 39.7 \\
\hline Night & 101 & 54.0 & 103 & 51.8 \\
\hline
\end{tabular}

${ }^{a}$ Multiple answers possible (percent do not add 100).

this study was aimed to assess the prevalence of occupational hazards and associated factors among nurses working in Jimma zone public hospitals.
The overall prevalence of occupational hazards in the study area was $78.3 \%$. Blood/body fluid exposure during the last 6 months was $62.6 \%$ while needle stick/sharp injuries during the same period was found to be $58.8 \%$; implying that, blood/body fluid exposures and NSIs are common occupational hazards to the participants. This finding is in line with a study from Turkey where the prevalence was 57\% (19). Majority of NSIs among nurses occurred by syringe needle as most procedures in a clinical setting involve administering intravenous/intramuscular injections or the drawing of blood which is almost comparable with study done in Saudi Arabia (63\%) (20).

Risks of sharp injuries varied between different working units. In this study, $21 \%$ of exposures occurred in the surgical ward. This result is consistent with the study finding from tropical Australian hospital (23.9\%) (12). Prevalence of sharp injuries in intensive care unit $(3.1 \%)$ was also comparable with the finding of study conducted in British Columbia (3.0\%) (21).

The proportion of nurses experienced blood exposure in this study is similar to that of southern Iran in which blood was the most frequent contaminant (87\%). The exposure most commonly occurs during inserting or removing intravenous lines and the high prevalence might be due to insufficient number of nurses, lack of adherence to standard precautions, and improper disposal of medical wastes (22).

Sex of respondents was also significantly associated with occupational hazards; the odds of exposure were two times higher among male nurses than females. This is consistent with the report from the duke health and safety surveillance system (5). The possible explanations might be men are less likely to use universal precautions but further studies are warranted to identify exposure differences, especially in nursing staff who perform similar tasks.

Marital status was found to have significant association with occupational hazards. Single participants had increased risk of encountering occupational hazards compared to ever married ones. The possible explanation might be married nurses feel more responsible than the single ones which increase their chance of adhering to universal precautions but further studies are required to produce solid evidences.

Training on infection prevention was the other predictor of occupational hazards. Nurses who had no training on infection prevention were six times more exposed to risk of occupational hazards than those who had. This result is in line with the study finding from sub-Saharan Africa (23). In this study $73 \%$ of the respondents had never been trained on infection prevention and safety precautions; which shows poor culture of the health facilities in practicing safety first principle. This might be the reason behind the high prevalence of blood/body fluid exposure and needle stick/sharp injury; as training activities in nursing increases the chance of the trainees to get up-to-date information about infection prevention mechanisms (24), promote job satisfaction, increase retention of nurses, and even enable continued provision of quality care (25).

Nurses working in chronic illnesses follow-up clinic were less likely to have occupational hazards than those nurses working in surgical ward. similar finding was obtained in tropical Australian hospital (12) and China (26) where nurses working in maternity/ 
TABLE 5 | Bivariate and multivariate logistic regression model among nurses working in Jimma zone public hospitals, south west Ethiopia, 2016.

\begin{tabular}{|c|c|c|c|c|c|}
\hline \multirow[t]{2}{*}{ Variables } & & \multicolumn{2}{|c|}{ Occupational hazards } & \multirow[t]{2}{*}{ COR $[95.0 \%$ confidence interval $(\mathrm{Cl})]$} & \multirow[t]{2}{*}{ AOR $(95.0 \% \mathrm{Cl})$} \\
\hline & & Yes $(N=249)$ & No $(N=69)$ & & \\
\hline \multirow[t]{2}{*}{ Sex } & Female & 112 & 45 & 1 & \\
\hline & Male & 137 & 24 & $2.29(1.32,3.99)$ & $2.20(1.09,4.40)^{\star}$ \\
\hline \multirow[t]{2}{*}{ Marital status } & Ever married & 99 & 45 & 1 & \\
\hline & Single & 150 & 24 & $2.84(1.63,4.96)$ & $2.26(1.09,4.69)^{\star}$ \\
\hline \multirow[t]{3}{*}{ Age category } & $\geq 30$ years & 43 & 19 & 1 & \\
\hline & $\leq 24$ years & 86 & 20 & $1.90(0.92,3.93)$ & \\
\hline & $25-29$ years & 120 & 30 & $1.77(0.90,3.46)$ & \\
\hline \multirow[t]{2}{*}{ Training on infection prevention } & Yes & 46 & 40 & 1 & \\
\hline & No & 203 & 29 & $6.09(3.42,10.82)$ & $5.99(3.14,11.41)^{\star}$ \\
\hline \multirow[t]{2}{*}{ Position in the hospital } & Clinical staff manager & 20 & 15 & 1 & $2.20(0.89,5.42)$ \\
\hline & Clinical staff nurse & 229 & 54 & $3.18(1.53,6.61)$ & \\
\hline \multirow[t]{10}{*}{ Working unit } & Surgical ward & 52 & 12 & 1 & \\
\hline & Medical ward & 47 & 8 & $1.36(0.51,3.60)$ & \\
\hline & Intensive care unit & 7 & 3 & $0.54(0.12,2.39)$ & \\
\hline & Major operation room & 17 & 4 & $0.99(0.28,3.45)$ & \\
\hline & Psychiatry & 7 & 3 & $0.54(0.12,2.39)$ & \\
\hline & Pediatrics ward & 39 & 4 & $2.25(0.67,7.51)$ & \\
\hline & Obstetrics and gynecology ward & 18 & 4 & $1.04(0.29,3.63)$ & \\
\hline & Ophthalmology unit & 9 & 4 & $0.52(0.14,1.97)$ & \\
\hline & Chronic illness follow-up clinic & 9 & 10 & $0.208(0.07,0.62)$ & $0.19(0.051,0.710)^{*}$ \\
\hline & OPD & 44 & 17 & $0.60(0.26,1.39)$ & \\
\hline
\end{tabular}

*Statistically significant.

NSIs, needle stick injuries; COR, crude odds ratio; AOR, adjusted odds ratio; OPD, outpatient department.

neonatal units were less likely to have occupational hazards compared to nurses working in medical or surgical wards.

\section{Limitations of the Study}

This study has shared the limitations of cross-sectional studies, the difficulty of determining causal relationships between variables. The instrument was prepared in English assuming respondents can understand the language and this may possibly cause some miss understanding in some words or terminology.

\section{CONCLUSION}

The prevalence of occupational hazard among nurses was found to be high. Blood/body fluid exposure accounts greater number than needle stick/sharp injuries. Being male and single was positively associated with occupational hazards; while having training on infection prevention and working in chronic illness follow-up clinic showed negative association. Working unit specific safety precautions and basic infection prevention in-service training may help the nurses to practice safety first principle and there by decrease blood/body fluid exposure and needle stick/sharp injuries as the safety of nurses themselves and subsequently, that of their patients, depend directly on the degree to which nurses can identify and control the varied occupational hazards specific to jobs.

\section{CONSENT TO PUBLISH}

Written consent was obtained from the respondents to publish the interview.

\section{AVAILABILITY OF DATA AND MATERIALS SECTION}

Data supporting this finding are available.

\section{ETHICS STATEMENT}

Ethical clearance was obtained from Jimma University, College of public health and Medical sciences, institutional review board. A formal letter of cooperation was written to the hospitals. Written consent was obtained from each study participant.

\section{AUTHOR CONTRIBUTIONS}

YBB wrote the proposal, participated in data collection, analyzed the data, and drafted the paper. BTL and GNG approved the proposal with some revisions, participated in data analysis. YMA participated in proposal development, data analysis, and wrote the manuscript. All authors read and approved the final manuscript.

\section{ACKNOWLEDGMENTS}

We are very grateful to Jimma University for the financial support and all study participants for their commitment in responding to our questionnaire.

\section{FUNDING}

Jimma University has covered the per diem for data collectors. 


\section{REFERENCES}

1. Healey BJ, Walker WT. Introduction to Occupational Health in Public Health Practice. 1st ed. Pennsylvania: Jossey-Bass A Wiley Imprint (2009). p. 1-328.

2. CDC. Workbook for Designing, Implementing and Evaluating a Sharps Injury Prevention Program. Centers for Disease Control and Prevention (2002). 1 p.

3. Rampal L. Needle stick and sharps injuries and factors associated among health care workers in a Malaysian hospital. Eur J Soc Sci (2010) 13(3):354-62.

4. CDC. The National Healthcare Safety Network (NHSN), Manual Healthcare Personnel Safety. Atlanta, GA: Centers for Disease Control and Prevention (2009). p. 3-1.

5. Dement JM, Epling ÃC, Østbye T, Pompeii LA, Hunt DL. Blood and body fluid exposure risks among health care workers: results from the duke health and safety surveillance system. Am J Ind Med (2004) 46:637-48. doi:10.1002/ ajim.20106

6. Wilburn SQ, Eijkemans G. Preventing needlestick injuries among healthcare workers: a WHO-ICN collaboration. Int J Occup Environ Health (2004) 10(4):451-6. doi:10.1179/oeh.2004.10.4.451

7. Sujatha NC. A Study to Assess the Knowledge and Practice Regarding Occupational Blood and Body Fluid Exposure among Staff Nurses in Selected Hospitals at Bangalore [Doctoral Dissertation]. Rajiv Gandhi University (2012). 136 p.

8. Mbaisi EM, Ng'ang'a Z, Wanzala P, Omolo J. Prevalence and factors associated with percutaneous injuries and splash exposures among health-care workers in a provincial hospital, Kenya, 2010. Pan Afr Med J(2013) 14:10. doi:10.11604/ pamj.2013.14.10.1373

9. Zaidi MA, Beshyah SA, Griffith R. Needle stick injuries: an overview of the size of the problem, prevention \& management. Ibnosina J Med Biomed Sci (2010) 2(2):53-61. doi:10.4103/1947-489X.210971

10. Smith DR, Choe MA, Jeong JS, Jeon MY, Chae YR, An GJ. Epidemiology of needle stick and sharps injuries among professional Korean nurses. J Prof Nurs (2006) 22(6):359-66. doi:10.1016/j.profnurs.2006.10.003

11. Atlaw WD. Pattern of Occupational Exposure to Patients' Body Fluids among Health Care Workers in Tikur Anbesa University Hospital, Addis Ababa, Ethiopia. Addis Ababa: University of South Africa (2013). 95 p.

12. Smith DR, Smyth W, Leggat PA, Wang RS. Needlestick and sharps injuries among nurses in a tropical Australian hospital. Int J Nurs Pract (2006) 12:71-7. doi:10.1111/j.1440-172X.2006.00553.x

13. Yimechew BZ, Tiruneh G, Ejigu T. Occupational exposures to blood and body fluids (BBFS) among health care workers and medical students in University of Gondar Hospital, Northwest of Ethiopia. Glob J Med Res (2013) 13(3):17-23.

14. BoFED. General Profile of the Oromiya National Regional State Table, 2008. (2008). p. 1-15.

15. Small L, Pretorius L, Walters A, Ackerman MJ. A surveillance of needle-stick injuries amongst student nurses at the University of Namibia. Health $S A$ Gesondheid (2011) 16(1):8.
16. Wondwossen Desta Atlaw. Patterns of Occupational Exposure to Patients' Body Fluids among Health Care Workers in Tikuranbesa University Hospital, Addis Ababa, Ethiopia. Pretoria: University of South Africa (2013). Available from: http://hdl.handle.net/10500/11922

17. Smith DR, Wei N, Zhang YJ, Wang RS. Needlestick and sharps injuries among a cross-section of physicians in mainland China. Am J Ind Med (2006) 49:169-74. doi:10.1002/ajim.20261

18. Talas MS. Occupational exposure to blood and body fluids among Turkish nursing students during clinical practice training: frequency of needlestick/ sharp injuries and hepatitis B immunisation. J Clin Nurs (2009) 18:1394-403. doi:10.1111/j.1365-2702.2008.02523.x

19. Irmak Z, Baybuga MS. Needlestick and sharps injuries among Turkish nursing students: a cross-sectional study. Int J Nurs Pract (2011) 17:151-7. doi:10.1111/j.1440-172X.2011.01920.x

20. Jahan S. Epidemiology of needlestick injuries among health care workers in a secondary care hospital in Saudi Arabia. Ann Saudi Med (2005) 25(3):233-8.

21. Alamgir H, Cvitkovich Y, Astrakianakis G, Yu S, Yassi A. Needlestick and other potential blood and body fluid exposures among health care workers in British Columbia, Canada. Am J Infect Control (2008) 36(11):12-21. doi:10.1016/j. ajic.2007.03.005

22. Askarian M, Shaghaghian S, Gillen M, Assadian O. Body fluid exposure in nurses of Fars province, Southern Iran. Arch Iran Med (2008) 11(5):515-21.

23. Nsubuga FM, Jaakkola MS. Needle stick injuries among nurses in sub-Saharan Africa. Trop Med Int Health (2005) 10(8):773-81. doi:10.1111/j.1365-3156.2005.01453.x

24. Duffy VG. Effects of training and experience on perception of hazard and risk. Ergonomics (2010) 46:114-25. doi:10.1080/00140130303524

25. Davidson H, Folcarelli PH, Crawford S, Duprat LJ, Clifford JC. The effects of health care reforms on job satisfaction and voluntary turnover among hospital-based nurses. Med Care (1997) 35(6):634-45. doi:10.1097/00005650199706000-00008

26. Zhang X, Wang Z, Li T. The current status of occupational health in China. Environ Health Prev Med (2010) 15:263-70. doi:10.1007/s12199-010-0145-2

Conflict of Interest Statement: The authors declare that the research was conducted in the absence of any commercial or financial relationships that could be construed as a potential conflict of interest.

Copyright (c) 2017 Belachew, Lema, Germossa and Adinew. This is an open-access article distributed under the terms of the Creative Commons Attribution License (CC BY). The use, distribution or reproduction in other forums is permitted, provided the original author(s) or licensor are credited and that the original publication in this journal is cited, in accordance with accepted academic practice. No use, distribution or reproduction is permitted which does not comply with these terms. 